\title{
A new species of the lithistid sponge genus Manihinea (Demospongiae: Theonellidae) from Western Australian waters
}

\author{
Jane Fromont ${ }^{1}$ and Andrzej Pisera ${ }^{2}$ \\ 1 Department of Aquatic Zoology, Western Australian Museum, Locked Bag 49, Welshpool DC, \\ Western Australia 6986, Australia. \\ ${ }^{2}$ Institute of Paleobiology, Polish Academy of Sciences, ul. Twarda 51/55, 00-818 Warszawa, Poland.
}

\begin{abstract}
This report describes a new sponge species, Manihinea lynbeazleyae sp. nov., from the warm temperate marine region of Western Australia (Indian Ocean). The presence of tetraclone desmas, phyllotriaenes as ectosomal spicules, and pseudospherasters as the only microscleres place this species within the genus Manihinea. The only other presently extant species worldwide is the type species for the genus M. conferta Pulitzer-Finali, 1993, also from the Indian Ocean. The key characters which distinguish the present species from the type species for the genus are external morphological features and details of the microscleres and desmas.
\end{abstract}

KEYWORDS: taxonomy, systematics, sponges, Porifera, Manihinea, Indian Ocean

\section{INTRODUCTION}

The sponge genus Manihinea was first established by Pulitzer-Finali (1993) for the species M. conferta PultzerFinali 1993, recorded from the North Kenya Banks, East Africa at 110 to 115 metres depth. The species has not been reported since, nor have any new species been described in the genus. However, Kelly (2000) discussed several specimens from Micronesia, and Pisera and Lévi (2002) noted there are likely to be two new species requiring description, one from Micronesia for the specimens examined by Kelly, and another for material collected in the Caribbean. This paper describes the second species for the genus which was found in the Perth Canyon off Perth, Western Australia in the Indian Ocean (Figure 1).

A major research project is currently underway to describe the lithistid fauna of the Australian region of the Indian Ocean (Pisera and Fromont, in preparation). Prior to this project most research on Indian Ocean lithistids was in papers published from the 1880s to the 1920s on deep water expeditions. Two new species of lithistids were reported by Lendenfeld (1907) from north Western Australia, and no further studies have focussed on the recent lithistids of Western Australia until now. A few papers have more recently documented lithistids collected in shallow waters e.g. Vacelet and Vasseur (1965), Vacelet and Vasseur (1971) and Vacelet et al. (1976), but these studies were undertaken in the western Indian Ocean and not in Australian waters.
The new species of Manihinea described here is one of many new sponge species discovered as a consequence of recent deep water expeditions off the coast of Western Australia.

\section{MATERIALS AND METHODS}

The Perth Canyon, where this new species was found, cuts into the continental shelf west of Perth and is 22 kilometres seaward of Rottnest Island (Pattiaratchi and Woo 2009). It is long, narrow and steep-sided (Pattiaratchi and Woo 2009), and is 4,000 metres deep and $100 \mathrm{~km}$ long which is larger than the Grand Canyon in the USA (http:// www.pewtrusts.org/news_room_details.aspx?id=49186, $20^{\text {th }}$ December, 2009). It is a known feeding area for pygmy blue whales (Rennie et al. 2006).

The Perth Canyon was sampled for biota as part of the 'Voyage of Discovery' Expedition to the deeper waters (greater than 100 metres deep) off south Western Australia undertaken by CSIRO and collaborators on the Southern Surveyor in 2005 (SS10/2005). This was the first expedition to collect sponges from the Canyon and the deeper waters off south Western Australia. At many stations sponges dominated (by weight) the fauna collected at the 100, 200 and occasionally 400 metre depth contours. A total weight of 31 kilograms of sponges was collected from the 200 metre depth contour in a single 10 minute tow (tow distance of 662 metres) in the Canyon, and in this haul 55 demosponge species were detected. 


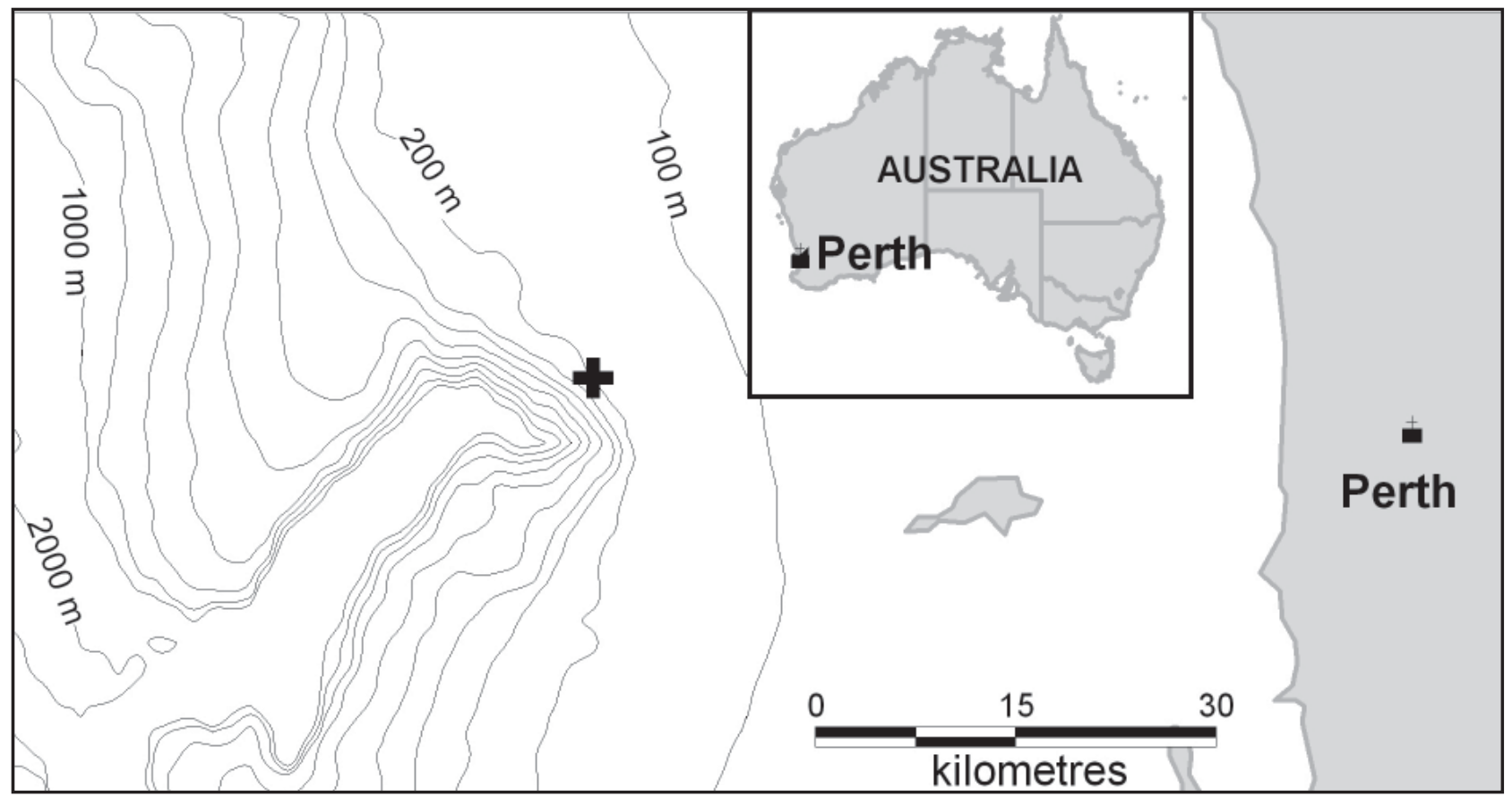

FIGURE 1 Map of location of Manihinea lynbeazleyae sp. nov.

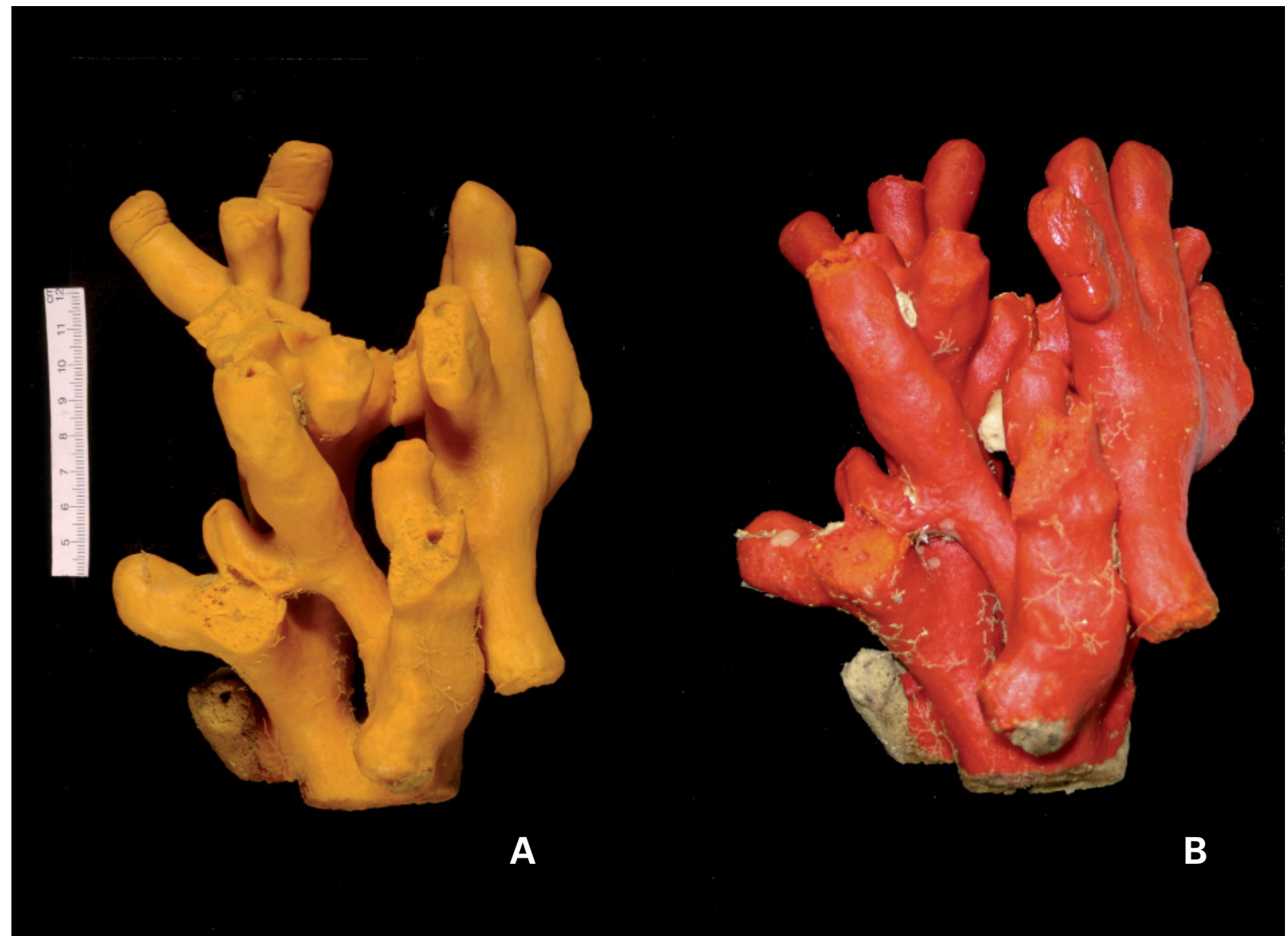

FIGURE 2 Manihinea lynbeazleyae sp. nov., holotype: A, preserved colour; B, deck image showing live colour. 
The specimen was preserved in $75 \%$ ethanol. Skeletal structure and spicule morphology were examined using light microscopy and scanning electron microscopy (SEM). Spicules were prepared by boiling small pieces of sponge (including the ectosome and choanosome) in concentrated nitric acid, followed by two consecutive washes with both distilled water and absolute alcohol. The resulting spicule extracts were dried on a glass coverslip attached to an SEM stub, and sputter coated with platinum prior to examination. Spicule dimensions were determined by measurement of 15 randomly selected spicules for each spicule type. The skeleton was prepared for examination by cutting a representative section at right angles to the surface of the sponge and attaching this to an SEM stub oriented with the ectosomal surface uppermost. Images were recorded with a Phillips XL20 scanning electron microscope, operating at $25 \mathrm{kV}$ (Institute of Paleobiology, Warszawa, Poland), and were saved electronically.

Abbreviations used in the text: MSNG: Museo Civico di Storia Naturale, Genova, Italy; WAM, Western Australian Museum, Perth, Australia.

\section{SYSTEMATICS}

\section{Family Theonellidae Lendenfeld, 1903}

\section{DIAGNOSIS (AFTER PISERA AND LÉVI 2002)}

Polymorphic; choanosomal spicules are tetraclone desmas; ectosomal spicules are phyllo- to discotriaenes; microscleres are spinose microrhabds and/or microxeas, and streptasters, and/or pseudospherasters which are believed to be derivatives of acanthorhabds or amphiasters; large choanosomal oxeas may be present.

\section{Manihinea Pulitzer-Finali, 1993}

Manihinea Pulitzer-Finali, 1993: 263.

\section{TYPE SPECIES}

Manihinea conferta Pulitzer-Finali, 1993, by monotypy.

\section{EMENDED DIAGNOSIS}

Clavate to massive arborescent sponges with deep and narrow axial cavity. Ectosomal spicules are exclusively phyllotriaenes; desmas are tetraclones; microscleres are pseudospherasters with massive spinose rays (most likely to be modified amphiasters or rhabds).

\section{REMARKS}

The new species described here and belonging to the genus Manihinea based on its spicule complement, has an arborescent morphology not observed in the type species, thus an emendation of the generic diagnosis was necessary to accommodate this difference.

\section{Manihinea lynbeazleyae sp. nov.}

(Figures 1-4)

\section{MATERIAL EXAMINED}

\section{Holotype}

Australia: Western Australia: 1 specimen, SS1005 station 69 (SS10/2005), Perth Canyon, West of Rottnest Island, $31.9210^{\circ} \mathrm{S} 115.2020^{\circ} \mathrm{E}$ to $31.9241^{\circ} \mathrm{S} 115.1960^{\circ} \mathrm{E}$, 194-232 m depth, 29 November 2005, epibenthic sled 'Sherman' (design described by Lewis 1999), on soft sediment, mean temperature $16.15^{\circ} \mathrm{C}$, J. Fromont on Southern Surveyor (WAM Z31539).

\section{DIAGNOSIS}

Manihinea lynbeazleyae sp. nov. is characterized by having a massive arborescent morphology, and a bright orange surface and yellow to orange interior. Ectosomal phyllotriaenes have narrow irregular clads (cladome 423-641 $\mu \mathrm{m}$ in diameter, rhabd 280-330 $\mu \mathrm{m}$ in length); microscleres consist of pseudospherasters (7.511 (maximum 16.1)) by 7.5- $9.5 \mu \mathrm{m}(\mathrm{n}=15)$, and slightly tuberculated tetraclone desmas (430-460 $\mu \mathrm{m}$ average) form a dense choanosomal skeleton.

\section{DESCRIPTION}

Habitus as in Figure 2. A massive arborescent sponge, about $19 \mathrm{~cm}$ high and $14 \mathrm{~cm}$ wide, with branches 1.5 to 2.5 $\mathrm{cm}$ in diameter, with deep and narrow axial cavities about 3-5 $\mathrm{mm}$ in diameter, that terminate as apical oscules.

Colour: in the live state bright orange exterior (Figure $2 b)$, bright orange-yellow interior; exterior dark yellow in ethanol (Figure 2a).

General organization: (Figure 3). Ectosome smooth, without any protruding spicules; inhalant pores dispersed over most of the surface, displaying openings 60-70 $\mu \mathrm{m}$ in diameter (Figure 3a). In the ectosomal region a dense layer of microscleres occurs between branches of the phyllotriaenes (Figure 3a, b). The desmas form a relatively dense choanosomal skeleton by articulation at their tips, but tips-to arms articulation was also observed (Figure $3 \mathrm{c}-\mathrm{f})$. The surface of the desma choanosomal skeleton displays numerous small openings that are 700-880 $\mu \mathrm{m}$ in diameter. Styles were rare in the choanosomal skeleton.

Spicules (Figure 4). Ectosomal megascleres are poorly branched phyllotriaenes with irregular narrow branches, cladome 423-641 $\mu \mathrm{m}$ in diameter, rhabd narrow, conical, pointed, 280-330 $\mu \mathrm{m}$ in length (Figure 4a-e). Desmas are regular to irregular tetraclones that bear sparse tubercles, especially toward the articulation region, that are 430$460 \mu \mathrm{m}$ on average in size (Figure $3 \mathrm{~d}$, e). Choanosomal styles are about $6 \mu \mathrm{m}$ thick and a minimum 600-800 $\mu \mathrm{m}$ long (total length is unknown because all were broken). Microscleres are strepaster-like (Figure 4g, i-j) to irregular pseudospherasters (Figure 4h, m, o), most probably modified streptasters, which have short, massive pointed and spinose rays, size is 7.5-11 (maximum 16.1) by 7.5- 9.5 $\mu \mathrm{m},(\mathrm{n}=15$, Figure $4 \mathrm{f}-\mathrm{o})$. 

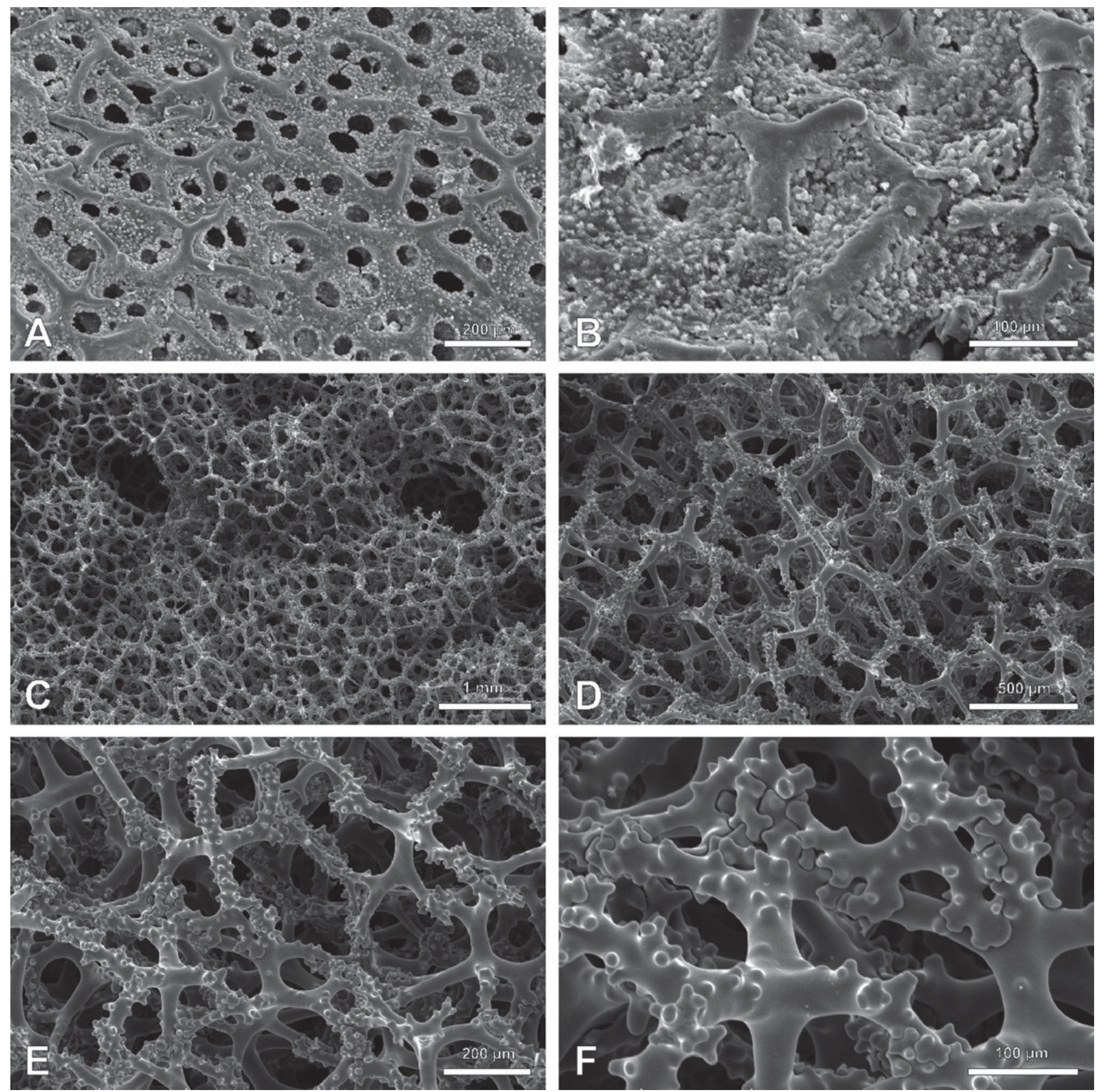

FIGURE 3 SEM images of skeleton of Manihinea lynbeazleyae sp. nov., holotype: A, ectosomal skeleton displaying inhalent pores; $B$, dense layer of microscleres between phyllotriaenes in ectosomal region; C-D, dense choanosomal skeleton; E-F, choanosomal desmas displaying sparse tubercles.

\section{REMARKS}

The holotype of the type species for the genus, Manihinea conferta (MSNG 48296) from North Kenya Banks, East Africa, Indian Ocean, 110-115 m depth, was examined and compared to the new species described here. The new species has a completely different external morphology, being arborescent, in comparison to $M$. conferta which is clavate. The spicule complement of both species is identical, but each spicule type has clear differences in detail. The ectosomal phyllotriaenes have a larger cladome and longer rhabd and the pseudospherasters are more irregular in shape grading into streptaster-like forms, and are not as densely and finely spined as those in $M$. conferta. The tetraclone desmas are also less regularly developed and more tuberculated in the new species. The choanosomal styles are thinner in the new species.

\section{DISTRIBUTION AND HABITAT}

Manihinea lynbeazleyae is found in the Perth Canyon in the Indian Ocean off Western Australia. This is a warm temperate region. It is a deep water species found at between 194-232 metres depth on soft sediment. This species has not been found elsewhere. 


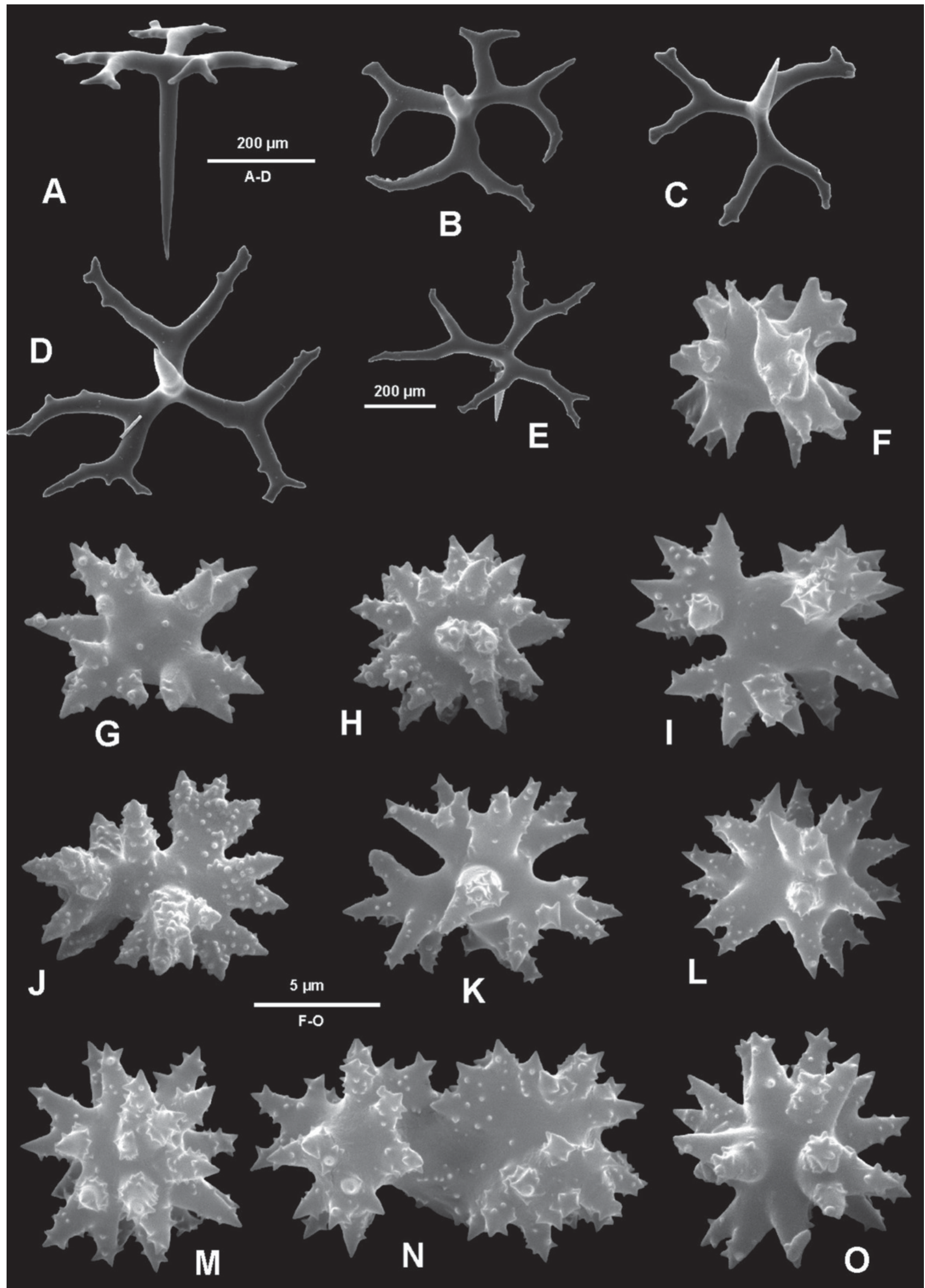

FIGURE 4 SEM images of spicules of Manihinea lynbeazleyae sp. nov., holotype: A-E, details of phyllotriaenes; F-O, irregular pseudospherasters. 


\section{ETYMOLOGY}

Named after Professor Lyn Beazley, Chief Scientist of Western Australia, for her dedicated advocacy of taxonomic science in Western Australia and her strong support of sponge research.

\section{DISCUSSION}

In this new species of Manihinea we have found 'pseudospherasters'. In some instances these spicules are almost spherical giving the impression that the rays could emanate from a single point while in many other instances the spicules are streptaster-like, with rays appearing to emanate from more than one point. These spicules may have originated by modification (hypersilification) from some form of streptaster. At this stage we use the term 'pseudospheraster' to indicate that their morphology is suggestive of a 'false' spheraster.

The position of the genus Manihinea in the Theonellidae is a special one because of the presence of pseudospherasters (described as true spherasters by Pulitzer-Finali, 1993), which are unknown in other genera of the family. The presence in both species of Manihinea of microscleres that are most likely of streptaster origin and grade into spheraster-like forms, suggest that these microscleres have the same origin. We have additional specimens that will assist in determining the formation of these spicules, and the results of this work will be discussed in a future publication.

The presence of these spicules places this genus close to Racodiscula, which has acanthorhabds typical for Theonellidae, and also amphiaster/strepaster-like microscleres. We consider that the continued inclusion of Racodiscula and Manihinea in Theonellidae is still justifiable because they have tetraclone desmas and phyllotriaenes as ectosomal spicules typical for Theonellidae, but they form a clear subgroup within the family because of the presence of streptaster/amphiasterlike microscleres. To fully resolve the morphology of these spicules and the location of the genera within Theonellidae will require the study of additional material referred to above.

\section{ACKNOWLEDGEMENTS}

We thank CSIRO Wealth from Oceans for funding the expedition, and the following CSIRO staff: Alan Williams for inviting Western Australian Museum staff to participate in the expedition and facilitating and funding the sponge research, Franzis Althaus for compiling Figure 1 and along with Felicity McEnnulty, providing details of the expedition, and Karen GowlettHolmes for the image in Figure 2b. We thank Grażyna Dziewińska (Institute of Paleobiology, Warszawa) for supplying the image in Figure 2a. We thank Mark Salotti, Western Australian Museum, for compiling Figure 2. Many thanks to the crew and expeditioners of the Southern Surveyor for their assistance with the sponge hauls.

\section{REFERENCES}

Kelly, M. (2000). Description of a new lithistid sponge from northeastern New Zealand, and consideration of the phylogenetic affinities of Corallistidae and Neopeltidae. Zoosytema 22: 265-283.

Lendenfeld, R. Von (1903). Porifera. Tetraxonia. Pp. vi-xv, 1-168. In: Schulze, Franz Eilhard (ed.), Das Tierreich. 19. Friedländer: Berlin.

Lendenfeld, R. Von (1907). Die Tetraxonia. Wissenschaftliche Ergebnisse der Deutschen Tiefsee-Expedition auf der Dampfer 'Valdivia' 1898-1899 11(1-2): i-iv, 59-374, pls IX-XLVI.

Lewis, M. (1999). CSIRO-SEBS (Seamount, Epibenthic Sampler), a new epibenthic sled for sampling seamounts and other rough terrain. Deep-Sea Research Part I-Oceanographic Research Papers 46: 1101-1107.

Pisera, A. and C. Lévi. (2002). Family Theonellidae Lendenfeld. In: J.N.A. Hooper and R.W.M. Van Soest (eds), Systema Porifera. pp. 327-337. Kluwer Academic/Plenum Press: New York etc.

Pattiaratchi, C. and Woo, M. (2009). The mean state of the Leeuwin Current system between North West Cape and Cape Leeuwin. In: K. Meney and M. Brocx (eds). The Leeuwin Current 2007 Symposium. Journal of the Royal Society of Western Australia 92: 221-241.

Pulitzer-Finali, G. (1993). A collection of marine sponges from East Africa. Annali del Museo Civico di Storia Naturale Giacomo Doria 89: 247-350.

Rennie, S. J., McCauley, R. D., and Pattiaratchi, C. (2006). Thermal structure above the Perth Canyon reveals Leeuwin current, undercurrent and weather influences and the potential for upwelling. Marine and Freshwater Research 57: 849-861.

Vacelet, J. and Vasseur, P. 1965. Spongiaires des grottes et surplombs des récifs de Tuléar (Madagascar). Recueil des Travaux de la Station marine d'Endoume 2-4: 71-123.

Vacelet, J. and Vasseur, P. 1971. Éponges des récifs coralliens de Tuléar (Madagascar). Téthys, Supplément 1: 51-126.

Vacelet, J. Vasseur, P. and Lévi C. (1976). Spongiaires de la pente externe des récifs coralliens de Tuléar (Sud-Ouest de Madagascar). Mémoires du Muséum National d'Histoire Naturelle, Série A, Zoologie 49: 1-116.

MANUSCRIPT RECEIVED 8 FEBRUARY 2010; ACCEPTED 8 APRIL 2010. 